\author{
W. Jean Yeung, John F. Sandberg, Pamela E. Davis-Kean, Sandra L. Hofferth \\ University of Michigan
}

\title{
Children's Time With Fathers in Intact Families
}

This paper uses the Panel Study of Income Dynamics to examine children's involvement with their fathers in intact families as measured through time spent together. Our findings suggest that although mothers still shoulder the lion's share of the parenting, fathers' involvement relative to that of mothers appears to be on the increase. A "new father" role is emerging on weekends in intact families. Different determinants of fathers' involvement were found on weekdays and on weekends. Fathers' wages and work hours have a negative relationship with the time they spend with a child on weekdays, but not on weekends. Mothers' work hours have no effect on children's time with fathers. On weekends, Black fathers were found to be less involved and Latino fathers more involved with their children than are White fathers. The weekday-weekend differential suggests that a simple gender inequality theory is not sufficient in explaining the dynamics of household division of labor in today's American families.

Social expectations of the father's role in the family have changed considerably in the past $3 \mathrm{de}-$ cades. Previously expected to be mainly an economic provider, the "new father" now is expected to also provide day-to-day physical and emotional care to children as an equal partner of the mother (Goldscheider \& Waite, 1991). Despite changing

Institute for Social Research, University of Michigan, Ann Arbor, MI 48106 (jeany@umich.edu).

Key Words: family time use, fathers' involvement, household division of labor, parent-child relationship. expectations, research based on data collected from the 1960s to the 1980s shows that although the level of paternal involvement has increased (Lamb, Pleck, Charnov, \& Levine, 1985; Pleck, 1985), fathers continue to devote significantly less time than mothers to the rearing of their children (Acock \& Demo, 1994). Moreover, although some fathers may have become more involved with child-rearing responsibilities, an increasing number of children have little or no contact with their biological fathers (Furstenberg, 1988). Recent longitudinal research has shown a unique and longterm benefit of paternal involvement to children's achievement and behavior (Snarey, 1993; Harris \& Marmer, 1996; Yeung, Hill, \& Duncan, 2000). This leads some policy analysts to suggest that uninvolved fatherhood is the root of a myriad of contemporary social problems and to call for strengthening fathers' family role as a solution.

Estimates of fathers' involvement vary widely for many reasons. Generalization and comparison over time or across age groups from results in previous research are difficult because studies on this topic differ in the samples used, the ages of the children covered, and the methodology employed in accounting for paternal involvement. Many of them are based on data collected from small local samples more than a decade ago, and most focus on fathers' involvement with infants and preschoolers (see Pleck, 1997, for a review).

This article examines interaction between children and their fathers, with children's time diaries reported mostly by mothers and children. We address the following research questions: (a) How much time do today's children in intact families spend with their fathers? (b) Given the stronger 
economic role of mothers, does time children spend with fathers, relative to that with mothers, increase? (c) How do characteristics of the child and parents affect the level and nature of time children and fathers share together? The main contribution of this article is our empirical work that can advance our understanding in fathers' involvement in the following ways. First, our work is based on a nationally representative sample that allows us to generalize our findings to the entire United States. Second, our sample includes children aged 0 to 12 , which allows us to compare the nature of paternal involvement across children's developmental stages. Third, the new data collected in 1997 allow us to compare the paternal involvement patterns to those in the 1960s and 1980s and to observe changes over the last several decades. Fourth, we use detailed children's timediary data that allow a more in-depth look at children's interaction with fathers than traditional survey data allow. Finally, the time-use data obtained for both weekends and weekdays allow us to examine fathers' time allocation relative to mothers' over a week. The definition of fathers' involvement in this article is limited to those that require the physical proximity of the fathers, however. Thus, activities that may entail cognitive or emotional investment of fathers when they are not physically near their children, such as setting up a college fund or searching for a good health insurance policy for a child while he or she is at school, are beyond the scope of this article.

We restricted our sample in this article to children who lived with both their biological or adoptive parents because research has noted substantial across-family variability in fathers' roles (Furstenberg, 1988). Children's interaction with nonresident fathers or other father figures in the family including stepfathers, relatives (such as uncles or grandfathers), or nonrelatives (such as boyfriends of the mothers) warrants separate examination. We examine children's time with fathers on weekends and on weekdays separately in light of research demonstrating the qualitative difference between the two in the allocation of household responsibility (Manke, Seery, Crouter, \& McHale, 1994). The weekday-weekend differentiation will help illuminate whether fathers substitute for mothers during workdays and whether fathers become more involved on weekends when time is less constrained by labor market activities. Previous studies suggest that because weekend days are less constrained by work schedules, gender- based inequalities in domestic labor may be most apparent on weekends (Manke et al.).

We begin with a review of past literature on paternal involvement in the next section and then proceed to describe the data and measures used. Our results are presented in three parts: (a) absolute level of paternal involvement, (b) fathers' involvement relative to that of the mothers', and (c) multivariate analyses of the determinants of paternal involvement. We conclude with a discussion of the implications of our findings for men's family roles and the household division of labor.

\section{Previous Literature}

\section{Absolute Levels of Paternal Involvement}

Results from previous research on levels of paternal involvement vary considerably for reasons noted above. The widely disseminated figure of 12 minutes a day of paternal engagement in child care cited in The Second Shift (Hochschild \& Machung, 1989) contrasts sharply with other available estimates. Some studies distinguish two levels of paternal involvement proposed by Lamb and colleagues (1985): (a) paternal engagement, defined as the amount of time a father interacts directly with a child and (b) paternal accessibility, defined as the time a father is available to a child but not directly involved with the him or her. McBride and Mills (1993), based on 100 predominantly White, middle-class families with children between the ages of 3 and 5 who lived with both biological parents in two Midwestern communities, estimated that fathers were engaged with children for 1.9 hours on weekdays and 6.5 hours on Sundays. Using data collected in 1986 on time fathers spent with children aged 10 to 15 , IshiiKuntz (1994) reported that fathers were directly engaged for 1 hour on weekdays and 2 hours on Sundays with sons and for 0.5 hours on weekdays and 1.4 hours on Sundays with daughters. Estimates of levels of accessibility range from 2.8 hours per day for adolescents (Almeida \& Galambos, 1991) to 4.9 hours on weekdays and 9.8 hours on Sundays for younger children (McBride \& Mills).

\section{Relative Levels of Paternal Involvement}

Studies focusing on the household division of labor often are concerned with fathers' involvement relative to that of mothers. Averaging across studies conducted in the 1980s and 1990s, Pleck 
(1997) estimated that fathers' proportional engagement was more than two fifths of mother's $(43.5 \%)$ and that their accessibility was nearly two thirds that of mothers $(65.6 \%)$. Comparing these figures with estimates averaging across studies in the 1970s and 1980s, Pleck concluded that there has been a clear increase in paternal engagement over the past 3 decades. Levant, Slattery, \& Loiselle (1987) reported an engagement ratio of 0.45 and an accessibility ratio of 0.43 for fathers in two-parent families with school-age daughters. Estimates in McBride and Mills (1993), based on a middle-class sample and representing an extreme high end in the literature, showed that fathers had engagement and accessibility levels of about $83 \%$ and mothers had levels of about $82 \%$.

\section{The Nature of Paternal Involvement}

Empirical evidence concerning the types of activities in which fathers are involved is more consistent. In examining trends in fathers' time use, Robinson and Godbey (1997) concluded that much the same in the 1980s (as in the 1960s), most of the time men spent with their children was in the form of "interactive activities," such as play or helping with homework, rather than in the "custodial" cleaning and feeding that are the mother's domains. Similarly, McBride and Mills (1993) reported that if fathers are involved with children, they are involved in play activities with them.

\section{Determinants of Paternal Involvement}

Pleck (1997) reviewed studies of paternal involvement by the child's characteristics and paternal characteristics and noted a rather complex picture. Existing research reveals that no single predictor exerts a predominant influence on paternal involvement. Furthermore, hardly any predictor of paternal involvement is consistently significant.

Developmental psychologists have long recognized that parental involvement with children varies by a child's age and gender, as well as by the parents' life-course stage. Among the most consistent findings in the literature is the lower level of paternal involvement, in absolute terms, with older children (Barnett \& Baruch, 1987; Marsiglio, 1991; Pleck, 1985). Research is inconclusive on whether fathers spend more time or spend time differently with their sons than with their daughters. Snarey (1993) reported no difference in the hours spent or in the types of inter- action with sons and daughters. In contrast, Barnett and Baruch and others found that fathers prefer to interact with sons, and Lamb et al. (1988) found fathers to be more involved with daughters. From a life-course perspective, Tinsley and Parke (1987) noted that it was important to also take into account the age of the father because older and younger fathers may differ in their energy levels, health status, life styles, occupations, and education.

The education of parents often is used as an indicator of the quality of time children spend with their parents. It has been hypothesized that better educated parents are more concerned with their children's academic development; consequently, they spend more time with their children, especially in achievement-related activities. Better educated fathers also are hypothesized to be more involved because they are more knowledgeable about children's developmental need for positive paternal involvement (Bailey, 1993). Blair, Wenk, and Hardesty (1994) and Marsiglio (1991), for example, showed that fathers with more education have a higher level of positive engagement. Work hours, on the other hand, may have a negative association with the amount of time fathers spend with their children. Several studies have reported that fathers who have more stressful jobs tend to spend more hours at work and are less involved with their children (Nock \& Kingston, 1988).

No clear pattern of paternal involvement by the race/ethnicity of the parents has been found. Some studies report Black fathers to be more involved than White fathers (Allen, 1981; McAdoo, 1988), whereas others report Black fathers to have lower relative accessibility (Goldscheider \& Waite, 1991). No differences among Latino, Black, and European American fathers have been reported (Roopnarine \& Ahmeduzzaman, 1993), but research on Latino fathers is rare.

Family economists have contributed to the literature of parental investment in children with the concept of the "opportunity cost" of time spent in caring for children. The time parents invest in caring for children carries an opportunity cost of both the earnings forgone and the human capital accumulation forgone (Mincer \& Polacheck, 1974). Gustafsson and Stafford (1997) argued that there are trade-offs between investing in children and in themselves, or between investing in the husband and in the wife. Consequently, high-income fathers are expected to spend less time with children. Haas (1988), for example, found that fathers with higher incomes engaged in less physical 
care. Fathers' income has also been found to correlate with both the level and nature of paternal involvement, however. In a study of Black married fathers with children aged 3 to 5, Ahmeduzzaman and Roopnarine (1992) found that higher income fathers had more positive engagement with their children.

In addition to literature on determinants of the absolute level of paternal involvement, there are some theories about factors that affect the relative contribution of parents to child care and household tasks. Early economic models of the family assume that the family maximizes a single utility function or that one member makes all resource allocation decisions. The more recent cooperative or noncooperative "bargaining models" allow individual family members to differ in their objectives and to bargain for resources available within the family based on the composition of family income (Lundberg \& Pollak, 1997). A body of literature posits that the power relation between spouses affects the household division of labor (Coverman, 1985; Farkas, 1976). According to this research, the relative power of partners derives from their command over resources, which are often measured by the earnings of the husband and the wife. Implicit in this literature is that domestic labor is undesirable and thus performed by those with less power. Therefore, husbands can use their earnings to "buy out" sharing in household tasks, and wives can use their earnings to "buy" increased participation by their husbands (Goldscheider \& Waite, 1991). This literature often posits that the wife's earnings matter more than the husband's earnings in determining the relative contribution of the spouses. There is, nevertheless, no consistent relationship between the father's relative and absolute involvement and the mother's employment status; some find higher paternal involvement when the mother is employed (Pleck, 1985), whereas others do not (Gottfried, Bathurst, \& Gottfried, 1994).

In light of discussions in the literature, fathers' involvement may be viewed as a function of children's characteristics and a set of constraints and resources available to fathers. Resources include parents' human capital and income and their availability to care for children, whereas constraints may include other demands on the father, such as his work hours, number of children in the family, or the child's physical or mental limitations. We hypothesize that children will be more involved with better educated fathers, especially in achievement-related activities. Fathers' earnings and work hours, in contrast, are expected to have a negative effect on their levels of involvement with their children. According to the family economic bargaining models, the more mothers contribute to the family income, the more involved fathers are likely to be.

\section{MethoD \\ Sample}

Data used in this article are drawn from the 1997 Child Development Supplement to the Panel Study of Income Dynamics (Hofferth, DavisKean, Davis, \& Finkelstein, 1998). This supplement collected data from a nationally representative sample of approximately 2,400 families that had at least one child between the ages of 0 and 12 at the time of the interview. In addition to rich socioeconomic characteristics of the family, this supplement also collects detailed time diaries of children in these families. The sample for our analysis includes 1,761 children aged 0-12 who lived with both their biological or adoptive parents in 1997.

\section{Data Collection Procedure}

Data on children's time use were collected through the use of a time diary administered in the spring and the fall of 1997. Each family was asked to complete a diary for a preassigned random weekday and a weekend day. The diary was designed to gather information on a child's activities over the 24 hours of the assigned day, with the day beginning and ending at midnight. Of all our sample children, 1,738 of them had both a weekday and a weekend report, whereas 15 and 8 children respectively had only a weekend or a weekday diary report. All diaries are included in the analyses in this article.

The primary caregiver of the target child, in most cases the mother, was the preferred respondent in cooperation with the target child, when possible. For the sample used for this article, $60 \%$ of the diaries were completed by the child's mother alone, $12 \%$ were completed by the mother and the target child, $6 \%$ were completed by the child alone (all of these children were 9 years or older), and $15 \%$ were completed by someone else in the household, such as a grandmother or other relative. Information on who completed the instrument is missing for approximately $7 \%$ of the diaries. It therefore is important to bear in mind 
when interpreting the results the variation in respondents and the fact that data used in this paper were reported mostly by mothers.

Respondents were asked to complete a time grid for activities in which the target child participated during the assigned days. For each activity reported, respondents were asked to provide information about (a) the time the activity began and ended; (b) if the child was watching television or a video, what program/video the child was watching; (c) where the child was during that activity; (d) who was doing that activity with the child; (e) who else was there but not directly involved in that activity; and (f) what else was the child doing with the primary activity? This article only analyzes children's primary activities. To obtain as complete information as possible for the target day, field interviewers contacted respondents to review the diaries. When there were gaps in the times given or the diaries were incorrectly completed, the interviewers probed for better information from the respondents.

\section{Validity of the Time-Diary Data}

The validity of the time-diary data has been assessed extensively in previous literature (Juster, 1985). This method is generally considered preferable to other methods in measuring time use in large samples. Direct observation is impractical because of its cost, whereas simple recall methods of assessing daily time use may be less accurate (Juster). In addition, time diaries have been found to be as accurate, and possibly more accurate, in assessing actual time use than more expensive methods with presumably high validity. The latter include "beeper" studies in which respondents are asked to record their activities at random times during the day as signaled by an electronic beeper (Robinson, 1985). More traditional "stylized" questions that ask directly of the frequency and duration of time spent in various activities are affected by the predefined categorization of activities and possibly by systematic over- or underestimation on the part of respondents of their actual time use in those activities (Robinson; Stafford \& Duncan, 1985).

One potential problem with the use of time diaries to derive unbiased estimates of aggregate time use stems from the necessary restriction placed on the sampling frame with regard to when the data are collected. Types of activities engaged in and time spent in those activities vary seasonally, by the day of the week, and by the typicality of the day (Juster, 1985). Because the selection of the weekday and the weekend day was randomized, the sample is representative on this dimension. The typicality of the day was assessed by a question in the time-diary instrument "How typical was this day?," with response categories ranging from 1 (very typical) to 5 (not at all typical). Respondents rated $62 \%$ of the diaries collected as from days that were either 1 (very typical) or 2 (typical). Seven percent of the diaries were rated as being taken from a day that was "not typical at all." The mean response was 2.20 (with a standard deviation of 1.24), and the median response was 2. Finally, one rough test of data quality frequently used is the number and variety of distinct primary activities reported, with higher frequencies on both counts presumed to indicate better data quality (Juster). On average, children in our sample engaged in 22 to 26 discrete activities over the course of the day, representing, on average, about 11 to 14 different types of activities. These are comparable to an earlier time-use study of children in the early 1980s that used the same methodology (Timmer, Eccles, \& O’Brien, 1985).

\section{Measuring Fathers' Involvement With Time Diaries}

We use these children's time diaries to examine two levels of paternal involvement proposed by Lamb (1985): (a) paternal engagement with a child and (b) paternal accessibility to a child. Engagement is operationalized as the amount of time a child interacts directly with his or her father across a wide range of activities. The total time a child is engaged with his or her father was ascertained through summing up all the time segments where the father was reported to be doing an activity with a child. The second level of fathers' involvement - accessibility to a child-is defined as the time a father is available to a child but not directly involved with him or her. The total accessible time was ascertained by summing up all the time segments in which a father was reported to be at the same location as the child but not directly involved in the reported activity. The question of accessibility is asked for all children's activities except for those involving personal hygiene or sleeping to avoid sensitive probing on those personal habits. Note that data collected in these children's time diaries reflect the amount of time each child spent with his or her father in 
various activities, rather than the time a father spent with all his children.

We will also examine the types of activities in which children are involved with their fathers. Previous literature distinguishes involvement in personal care activities and involvement in play, leisure, or affiliative activities with children (Beitel \& Parke, 1998; Radin, 1993). Here we expand to include achievement-related, household, and social activities to examine fathers' involvement in children's intellectual and social development during their early childhood and school years. All time-diary primary activities are grouped into the following six major activity categories in our analyses:

1. Personal care activities, which include care the child received from the fathers such as bathing, changing, and grooming, as well as eating meals together at home and away from home

2. Play and companionship activities, which include both active and passive play and other types of leisure events

3. Achievement-related activities, which include time spent studying, doing homework, reading, and in educational lessons

4. Household activities, which include housework, shopping, and time the child spends caring for other children

5. Social activities, which include visiting, household conversations, religious activities, and participation in other social events

6. Other activities, which include time in school and day care, sleep time, and other activities not included in the previous five categories.

A detailed description of the coding scheme of the activities is available from the authors on request.

\section{Measures Used in Multivariate Analysis}

For our multivariate analyses of determinants of fathers' involvement, the following measures of the child's characteristics are included in the model: three dummy variables for child's age (3-5, 6$8,9-12$, with age $0-2$ being the omitted category) to capture the changing nature of the father-child relationship as a function of children's developmental stages; gender of the child $(1=$ boy, $0=$ girl); and three dummy variables indicating whether the child has any physical or mental condition that would limit or prevent his or her ability to do usual childhood activities such as playing or participating in games or sports, attending school (preschool or day care) regularly, or doing regular school work.

Fathers' characteristics examined here include (a) ethnicity, categorized as White, Black, Hispanic, and other; (b) educational attainment, measured as whether he received any postsecondary education; (c) age, measured with dummy variables characterizing whether the father is under 30 , aged 30 to 40 , or older than 40 at the time of the interview; (d) earnings measured in $\$ 10,000$ 1997 dollars, and (e) weekly work hours. Presser's (1988) work on shift work and child care demonstrated that to adequately examine parents' work constraints, one needs information about parents' work schedules over a week (i.e., during which hours do parents work on weekdays and weekends). Unfortunately, no reliable data beyond parents' weekly work hours are available in the PSID.

Mother's characteristics examined include her weekly work hours and her income as a proportion of the total family income. Mother's share of total family income is categorized into three groups: less than $25 \%, 25$ to $49 \%$, and more than $50 \%$. We tested whether fathers' involvement is significantly different between families in which mothers contribute no income at all and those in which mothers contribute some but less than $25 \%$ of the total income. The results show that there is no difference between these two groups. Mother's age and education are not included in the model because of their high correlation with father's age and education. We also include the number of children as a control variable that might affect fathers' time input to a child.

A series of Tobit models was estimated. This method is appropriate because many children spend no time in a given category of activity, and Tobit estimation corrects for this censoring at 0 minutes. For all our analyses, we treat weekend days and weekdays separately because there is likely to be considerable variation in the extent and nature of paternal involvement. Data are weighted to adjust for selection probability and the nonresponse rate.

\section{RESULTS}

Findings for the absolute level of paternal involvement are presented first, followed by estimates of fathers' involvement relative to that of mothers. Multivariate analyses of the determinants of pa- 
ternal involvement are presented at the end of this section.

As noted earlier, this article focuses on paternal involvement with children in intact families, which is shown in previous literature to be significantly higher than that in other types of families. Our results based on the PSID data show the same pattern. A child's direct engagement time with biological fathers averages an hour and 13 minutes on a typical weekday and 2 hours and 29 minutes on a weekend day for children in intact families. The corresponding estimates are 5 and 21 minutes for children who live only with their biological mothers (with or without a stepfather), 1:04 and 1:30 for those who live with only their biological fathers (with or without a stepmother), and 9 and 28 minutes for those who do not live with either biological parents.

Not all children were reported to have participated in activities that involved fathers. In our sample of children in intact families, $86 \%$ spent some time with their fathers (either engaged or accessible) on weekdays, whereas nearly all $(93 \%)$ reported some paternal involvement on weekends. About three quarters of the children received personal care from their fathers, two thirds were involved in play or companionship activities, one third spent time in achievement-related activities, and about one fifth spent time with fathers in household or social activities on weekdays. On weekend days, the proportion of children reporting paternal involvement in each activity category was higher.

\section{Absolute Level of Paternal Involvement}

There are substantial differences in both the absolute level of paternal involvement and the types of activities in which fathers are involved on weekdays and during weekends. Averaging across all age groups, a child in an intact family interacts directly with his or her father for 1 hour and 13 minutes on a weekday and 3.3 hours on a weekend day. The time fathers are accessible to their children is comparable to direct engagement time, bringing the total involvement time to about 2.5 hours on a weekday and 6.5 hours on a weekend day. Consistent with previous research, children of all ages spend the largest fraction of their time with fathers in play and companionship, $39 \%$ of direct engagement time. Next to play and companionship activities, personal care activities occupy most of father-child shared time. Of the personal care activities, fathers and children spend the most time eating meals at home, averaging about half an hour on weekdays. Time spent in achievement-related, household, or social activities is small. Direct engagement time with fathers in achievement-related activities averages 4 minutes, and accessible time averages about $10 \mathrm{~min}$ utes on weekdays.

On weekends, the proportion of time engaged in household and social activities increases to about $15 \%$ of the total father involvement time for each child. The time children spend in social activities with their fathers increases to about half an hour on weekends. Most of the time in social activities is spent in religious activities, followed by visiting and other organizational events, such as school functions.

Results of an examination by age of the child are presented in Tables 1 and 2. Table 1 presents the mean time a child is either directly engaged with the father or has the father available on a typical weekday. Table 2 presents comparable information for a weekend day. The analyses are conducted separately for children in four different developmental stages: infancy (ages 0-2), preschool years (ages 3-5), early school years (ages 6-8), and preteen years (ages 9-12). We test for the differences in means across the age groups with a Scheffe multiple comparison procedure. When a difference is significant at the .05 level, we place superscripts next to the mean indicating the groups from which the specific age group differs. The total time a child spends with his or her father in each major category of activity is presented in the first row of each category group, followed by time broken down into more specific activities in each category.

Consistent with previous literature, Table 1 shows that the absolute level of paternal involvement decreases as the child's age increases. The composition of shared activities also varies by the child's age. On a typical weekday, infants and toddlers (aged 0-2) interact directly or have their fathers accessible to them in all activities for a little more than 3 hours. This level of involvement decreases as the child's age increases to 2 hours and 15 minutes for those aged 9-12. For each age group, the total time involved is almost equally divided into time spent in direct interaction and time the father is accessible to but not directly engaged with the child.

Time in personal care with fathers engaged or accessible decreases as the child's age increases, from a total of 1 hour for infants to half an hour for those aged 9-12. The total time a child spends 
Table 1. Mean Time (Hours: Minutes) a Child is Engaged* With the Father or Has the Father ACCESSIBLE** ON A WEEKDAY

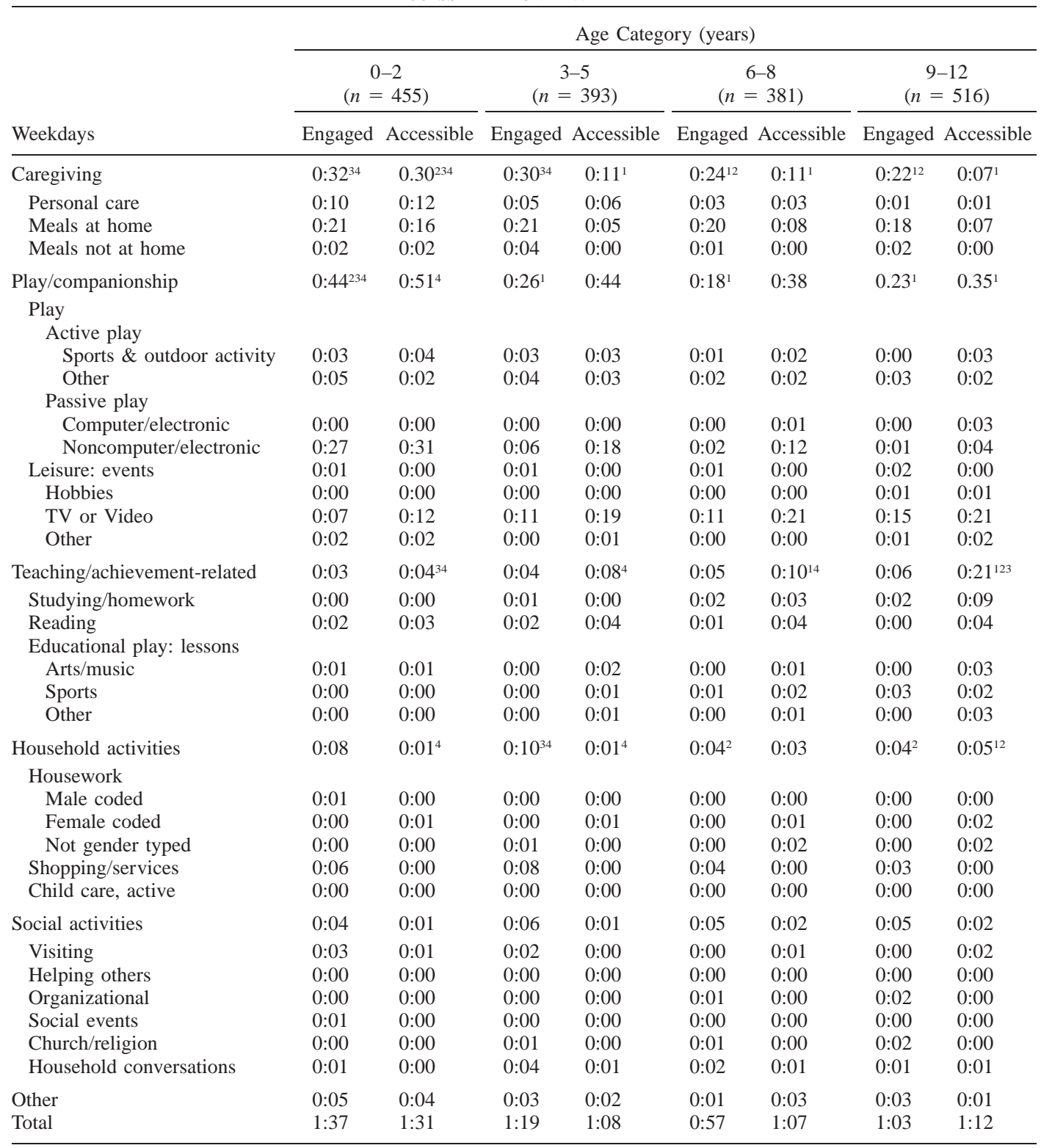

Note: Because of rounding, details may not add to total. The superscripts next to the mean indicate the group(s) from which the specific age group differs significantly at .05 level. * Time a child is directly interacting with the father. ** Time a child has the father available without direct interaction.

directly engaged with the father in activities such as washing, dressing, and medical care on a weekday averages $10,5,3$, and 1 minutes for each age group respectively.

Fathers are significantly more engaged with infants and toddlers in play and companionship activities than with older children (averaging 44, 26, 18, and 23 minutes, respectively, for each age group). Under the broad category of play and companionship activities, preschool children spend the most time with their fathers in passive noncomputer and nonelectronic play, which includes most indoor play such as playing board games, playing with toys, pretending, and playing house. On average, a $0-2$ year old spends 8 minutes on a weekday directly engaged, and 6 min- 
Table 2. Mean Time (Hours: Minutes) a Child is Engaged* With the Father or Has the Father ACCESSIBLE** ON A WEEKEND DAY

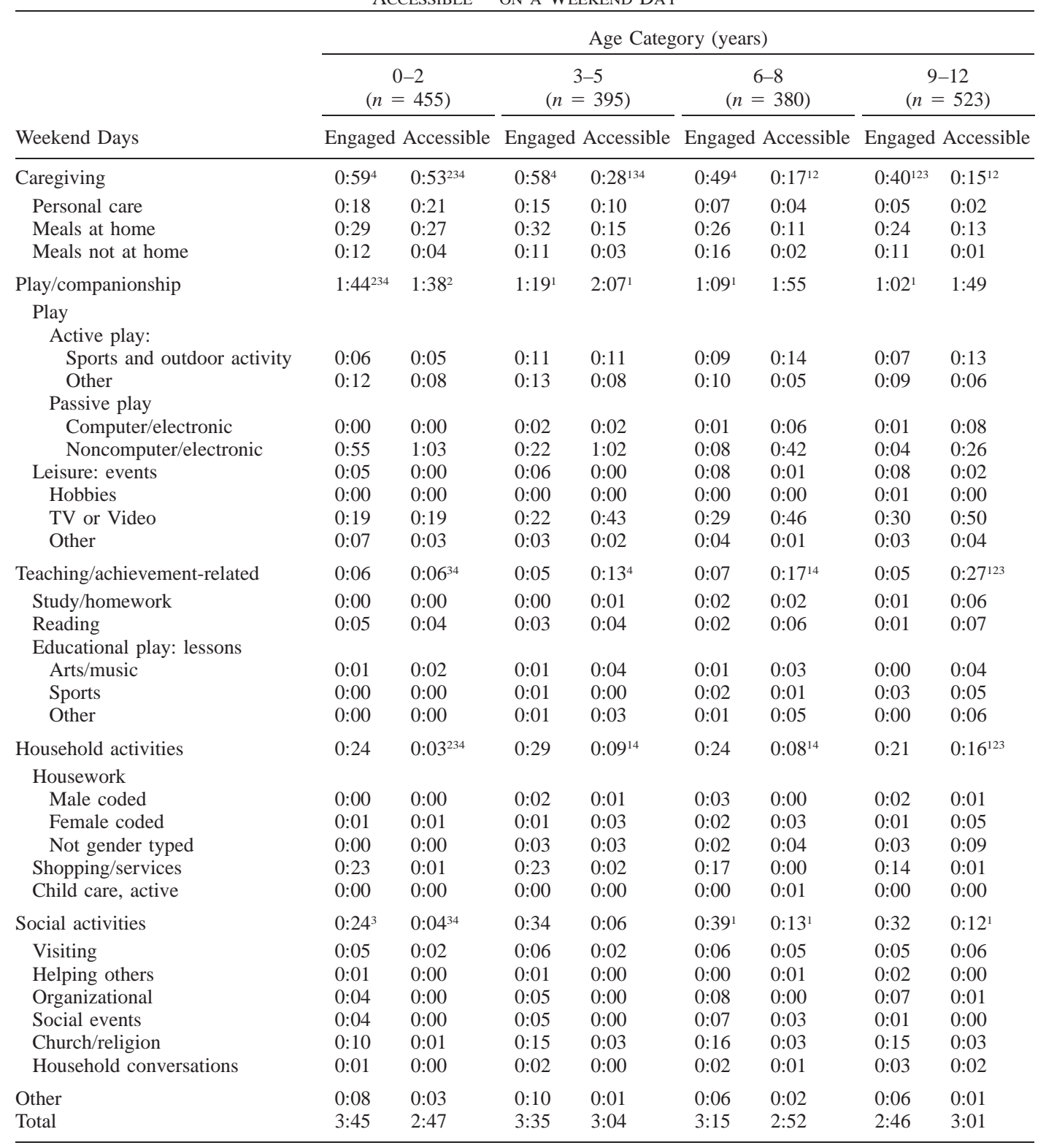

Note: Because of rounding, details may not add to total. The superscripts next to the mean indicate the group(s) from which the specific age group differs significantly at .05 level. * Time a child is directly interacting with the father. ** Time a child has the father available without direct interaction.

utes having father accessible in active play such as outdoor activities and sports. This time declines as children age. The time fathers are involved while children watch television or video tapes increases with the child's age. This reflects a general increase in time spent watching televisions and videos by the child's age. The total time fathers are engaged or accessible while watching televi- sions or videos increases from an average of 19 minutes per day for $0-2$ year olds to 30 minutes for 3-5 year olds, and over half an hour for 6-12 year olds. More than half of the time when children watch television or videos, fathers are not directly engaged but are only accessible to them.

The total time a child is involved with his or her father in achievement-related activities, which 
include reading, educational play, and studying, increases from 7 to 27 minutes across age groups on weekdays. The time spent studying and doing homework with the father is quite low. A schoolage child spent 2 minutes directly engaged and 3 9 minutes having his or her father accessible when studying or doing homework. Reading time together averages 0-2 minutes per weekday.

The average total (either engaged or accessible) time a child spent with the father in household activities averages 9, 11, 7, and 9 minutes across age groups. Among these activities, most of the time is spent shopping together. The total time spent in social activities averages 5-7 minutes, most of which is spent visiting together.

Table 2 presents children's involvement with fathers on a typical weekend day. As shown in Table 2, the amount of time in which a child is involved with his or her father more than doubles on weekend days compared with weekdays, with particularly notable increases in household and social activities. Of the caregiving activities, children spend 30 to 40 minutes eating meals together with their fathers (either at home or outside of the home) on a weekend day. The total time a child spends with his or her father in personal care activities on a weekend day averages almost 2 hours for infants and toddlers and declines to less than an hour for the oldest group.

Older children spend twice as much time watching television or videos on a weekend day than on a weekday. Indeed, they spend more time watching television or videos than in any other single type of passive or active play during weekends. For each of the four age groups, children spend, on average, 19, 22, 29, and 30 minutes respectively watching television or videos with their fathers and almost twice as much time with their fathers accessible while watching television or videos on a weekend day. The total time spent in active play on a weekend day averages about half an hour per day across age groups.

Time children spent with their fathers in studying, doing homework, or reading on weekends remains very low. Increased time spent together in household activities is mainly in shopping, and increased time in social activities result from religious activities on weekends.

\section{Fathers' Time Relative to That of Mothers}

Children's level of involvement with mothers and fathers is significantly different across all major activity categories for both weekdays and week- ends (test results not shown). Table 3 shows the ratios of fathers' to mothers' involvement by the child's age in each type of activity. The ratios represent fathers' involvement in a specific type of children's daily activity relative to that of mothers. A value of 1 indicates an equal contribution from mothers and fathers, and a value greater than 1.0 represents greater paternal participation. We show the ratios for direct engagement time, as well as those for total involvement, which includes time parents are accessible to children.

On weekdays, the total engagement time of children across the age groups with fathers is between $60 \%$ and $82 \%$ that of mothers. Whereas older children spend less time with their fathers, the level of involvement with fathers relative to that of mothers increases with child's age. This reflects an overall decrease in the time older children spend with both parents and a sharper decrease in time spent with mothers. Fathers have the lowest relative direct involvement in household and achievement-related activities. Fathers spend about a third of mothers' time for the first three age groups and about half of mothers' time for the oldest group in reading, educational play, or studying. The direct paternal engagement time in personal care activities is $62 \%$ of the mother's level, and it is particularly low for younger children, accounting for less than half of mothers' time with infants. This ratio increases to .88 for children aged 9 to 12, however. Consistent with previous research, children's relative engagement in play and companionship activities with their fathers is higher than in other activities, averaging $88 \%$ of their time with mothers for children of all ages. When we examine in detail the specific items under this category of activities, fathers' participation in many items is greater than that of mothers (data not shown). These activities include sports, outdoor activities, hobbies and television or video viewing. For preschoolers, fathers engaged 2.5 times as much in sports as mothers, 1.5 times as much in computer or electronic passive play, and slightly more than mothers in noncomputer play. For school-aged children, particularly the oldest group, fathers' time in most active play and leisure activities is greater than that of the mothers. For infants, mothers and fathers spend almost an equal amount of time watching television or videos with the child, in passive noncomputer play, and in other active play with them.

Fathers have a relatively greater share of interaction with children on weekends than on weekdays. Children's total engagement time with 
Table 3. Ratio of Fathers' to Mothers' Time Engaged With or Accessible to Children By Age of Child AND TYPES OF ACTIVITIES

\begin{tabular}{|c|c|c|c|c|}
\hline \multirow[b]{2}{*}{ Activity } & \multicolumn{2}{|c|}{ Weekday } & \multicolumn{2}{|c|}{ Weekend } \\
\hline & Engaged & $\begin{array}{l}\text { Engaged or } \\
\text { Accessible }\end{array}$ & Engaged & $\begin{array}{c}\text { Engaged or } \\
\text { Accessible }\end{array}$ \\
\hline \multicolumn{5}{|l|}{ All activities } \\
\hline All ages & 0.67 & 0.65 & 0.87 & 0.87 \\
\hline $0-2$ years & 0.60 & 0.67 & 0.80 & 0.87 \\
\hline $3-5$ years & 0.67 & 0.58 & 0.88 & 0.86 \\
\hline $6-8$ years & 0.70 & 0.61 & 0.94 & 0.88 \\
\hline $9-12$ years & 0.82 & 0.72 & 0.93 & 0.86 \\
\hline \multicolumn{5}{|l|}{ Caregiving } \\
\hline All ages & 0.62 & 0.74 & 0.78 & 0.90 \\
\hline $0-2$ years & 0.46 & 0.71 & 0.61 & 0.88 \\
\hline $3-5$ years & 0.67 & 0.72 & 0.81 & 0.91 \\
\hline $6-8$ years & 0.80 & 0.77 & 0.88 & 0.91 \\
\hline $9-12$ years & 0.88 & 0.81 & 0.96 & 0.91 \\
\hline \multicolumn{5}{|c|}{ Play/companionship } \\
\hline All ages & 0.88 & 0.62 & 1.04 & 0.88 \\
\hline $0-2$ years & 0.83 & 0.66 & 0.99 & 0.88 \\
\hline $3-5$ years & 0.81 & 0.53 & 1.03 & 0.85 \\
\hline $6-8$ years & 0.90 & 0.58 & 1.09 & 0.88 \\
\hline $9-12$ years & 1.09 & 0.72 & 1.10 & 0.85 \\
\hline \multicolumn{5}{|c|}{ Teaching/achievement-related } \\
\hline All ages & 0.45 & 0.64 & 0.83 & 0.89 \\
\hline $0-2$ years & 0.38 & 0.61 & 0.87 & 0.94 \\
\hline $3-5$ years & 0.33 & 0.52 & 0.57 & 0.89 \\
\hline $6-8$ years & 0.33 & 0.61 & 1.08 & 0.88 \\
\hline $9-12$ years & 0.56 & 0.73 & 1.00 & 0.89 \\
\hline \multicolumn{5}{|c|}{ Household activities } \\
\hline All ages & 0.44 & 0.54 & 0.68 & 0.75 \\
\hline $0-2$ years & 0.45 & 0.47 & 0.68 & 0.70 \\
\hline $3-5$ years & 0.56 & 0.56 & 0.71 & 0.77 \\
\hline $6-8$ years & 0.57 & 0.63 & 0.75 & 0.77 \\
\hline $9-12$ years & 0.25 & 0.52 & 0.63 & 0.78 \\
\hline \multicolumn{5}{|c|}{ Social activities } \\
\hline All ages & 0.80 & 0.70 & 0.94 & 0.90 \\
\hline $0-2$ years & 1.00 & 0.68 & 0.90 & 0.90 \\
\hline $3-5$ years & 0.87 & 0.72 & 0.98 & 0.94 \\
\hline $6-8$ years & 0.53 & 0.56 & 1.00 & 0.95 \\
\hline $9-12$ years & 0.88 & 0.80 & 0.91 & 0.94 \\
\hline
\end{tabular}

Source: 1997 Child Development Supplement to the Panel Study of Income Dynamics.

fathers is between 80 to $94 \%$ that of their time with mothers; again, this percentage is higher for school-aged children than for infants and preschoolers. Relative involvement in household activities remains the lowest across all categories, $68 \%$. Fathers' participation in personal care activities ranges from $61 \%$ of mothers' for infants to an increasingly equal share for older children. Results indicate that children spent slightly more time engaged in play and companionship activities with their fathers on weekends than with their mothers. This is particularly true for older children (1.10 for the 9-12 year olds). A closer examination shows that fathers' relative direct engagement is particularly high in certain types of play and companionship activities (data not pre- sented). For example, the amount of time fathers spend coaching or teaching a child sports is more than 5 times that spent by mothers among the 6to 8-year-olds, and almost 3 times higher for those aged 9 to 12. Paternal engagement in other outdoor play with 6- to 8-years-olds is 6 times that of mothers on weekends. Fathers' involvement in household activities remains low during weekends.

\section{Multivariate Analyses on Determinants of Fathers' Involvement}

In this section, we examine paternal involvement as a function of the characteristics of the child and 
Table 4. Descriptive Statistics for the Predictors Used in the Multivariate Analyses

\begin{tabular}{|c|c|c|c|}
\hline Variable & $n$ & Weighted Means & $S D$ \\
\hline Child's age & 1,753 & & \\
\hline 0-2 years (omitted) & & 0.27 & 0.44 \\
\hline $3-5$ years & & 0.23 & 0.42 \\
\hline $6-8$ years & & 0.21 & 0.41 \\
\hline $9-12$ years & & 0.29 & 0.45 \\
\hline Sex of child (boy $=1$ ) & 1,753 & 0.50 & 0.50 \\
\hline \multicolumn{4}{|l|}{ Child's functional limitation } \\
\hline Play & 1,750 & 0.03 & 0.19 \\
\hline Attend school & 1,745 & 0.01 & 0.09 \\
\hline Do school work & 1,741 & 0.01 & 0.12 \\
\hline Ethnicity of father & 1,753 & & \\
\hline White (omitted) & & 0.77 & 0.42 \\
\hline Black & & 0.07 & 0.26 \\
\hline Latino & & 0.11 & 0.31 \\
\hline Other & & 0.05 & 0.23 \\
\hline Father's earnings (in $\$ 10,000$ ) & 1,753 & 3.70 & 3.54 \\
\hline Father's weekly work hours & 1,753 & 44.70 & 12.72 \\
\hline Father's education & 1,753 & & \\
\hline High school graduate or lower (omitted) & & 0.45 & 0.47 \\
\hline Some college & & 0.55 & 0.52 \\
\hline Father's age & 1,753 & & \\
\hline Under 30 years (omitted) & & 0.17 & 0.37 \\
\hline $30-39$ years & & 0.52 & 0.50 \\
\hline 40 years or older & & 0.31 & 0.46 \\
\hline Wife's wage/total family income $(\%)$ & 1,753 & & \\
\hline No earning or Less than $25 \%$ (omitted) & & 0.59 & 0.48 \\
\hline $25 \%-49 \%$ & & 0.31 & 0.48 \\
\hline Half or more & & 0.10 & 0.31 \\
\hline Mother's weekly work hours & 1,753 & 24.60 & 19.78 \\
\hline No. of children under 18 in family & 1,753 & 2.24 & 1.03 \\
\hline
\end{tabular}

the family. Descriptive statistics for predictors are presented in Table 4.

The dependent variable in the models is the total time (in minutes) a child is either engaged with his or her father or has the father accessible. We also conducted analyses with fathers' engagement time only as the dependent variable. Results are similar and therefore not presented here. The one notable difference found in models for fathers' direct engagement time only is that the number of children has a significant negative effect on fathers' direct engagement time but not on their accessibility level. Tables 5 and 6 show the results of these analyses for weekdays and weekend days, respectively.

The differential fathers' involvement by age of the child seen in the bivariate analyses persists in the multivariate analyses. Older children spend less time with their fathers in personal care and play and companionship activities but more time in achievement-related and social activities. Boys spend 18 minutes more with their fathers than do girls in play and companionship activities on weekdays. We tested for interaction effects of the age and gender of children and found only one such effect: Older boys spend more time with their fathers in play and companionship activities (data not shown). A child's functional limitation also affects the levels of fathers' involvement. A child who has a limitation that keeps him or her from attending school or day care regularly spends about an hour more on a weekday and 1.5 hours more on a weekend day with his or her father in achievement-related activities than does a child without such limitations. A child who has a limitation that keeps him or her from regular child play spends half an hour more doing household activities on weekdays and less time playing on weekends with his or her father than does a child without such a limitation.

Many fathers' characteristics also affect their levels of involvement. On weekdays, children whose fathers have some college education are involved with them 17 minutes more than are children of fathers who do not have any college education. Most notably, fathers with some post secondary education spend about half an hour more on weekdays with children on achievement- 
related activities and 17 minutes more on social activities than do those without postsecondary education.

As hypothesized, fathers' earnings have a negative and significant effect on their involvement levels with children on weekdays, reflecting the opportunity cost of fathers' time. The magnitude of the effect seems relatively small, however. For every $\$ 10,000$ increase, there is a 3.5-minute decrease in fathers' total involvement on weekdays, 1 minutes less in caregiving, 3 minutes less in play activities, and 1.6 minutes less in achievementrelated activities. Fathers' weekly work hours also have a negative impact on time a child spends with his or her father. For every hour a father is at work, there is an associated 1-minute decrease in time a child spent with him on weekdays (mostly in play and companionship activities). Mothers' weekly work hours and wages, on the other hand, do not have the same impact. Overall, there is no evidence of an increase in fathers' child-care responsibilities on weekdays when the mother has a stronger economic role. Mothers' work hours have no effect on fathers' involvement on weekdays. The relationship of parents' work hours with fathers' time was tested for nonlinearity but no significant effects were found (data not presented). The mother's wage does not have much impact on fathers' involvement either. The only instance of such an effect is that when mothers contribute half or more of the total family income, fathers' involvement in personal care activities increases by 10 minutes on weekdays. There is a corresponding decrease in the amount of time fathers spend with a child in play, however. Thus, on balance, the effect of mothers' earnings on fathers' total time input is not statistically significant on weekdays. Puzzling to us is a significant negative effect of the mother's share of income on a child's time with his or her father in play and companionship activities on weekdays when the mother is working but contributes less than half of the total family income.

Interestingly, several predictors have a different effect on fathers' involvement on weekends. Although age of the child and fathers' educational attainment remain important predictors, father's ethnicity and mother's earnings become significant predictors of fathers' involvement on weekends: Black fathers spend 70 minutes less and Latino fathers spend about an hour more with a child than do White fathers. More detailed analyses reveal that Black fathers are significantly less involved on weekends in all types of activities ex- cept for social activities, whereas Latino fathers have a higher level of involvement in household and personal care activities. Fathers' earnings no longer have a negative effect on their level of involvement on weekends. On the contrary, for every $\$ 10,000$ increase in fathers' earnings, there is a 3-minute increase in time spent together in achievement-related activities on a weekend day. There is a positive relationship between mothers' contribution to total family income on children's time with fathers. Children with a mother who contributes to half or more of the total family income spend 48 minutes more with their fathers on weekends than do children with a mother who contributes less than a quarter of the total family income.

\section{CONCLUSIONS AND DisCUSSION}

We have presented a current national picture of the extent and nature of the involvement that American children in intact families have with their fathers, and we have examined the socioeconomic factors that may affect paternal involvement. On average, a child spends 1 hour and 13 minutes on a weekday and 3.3 hours on a weekend day interacting directly with his or her father and a comparable level of time with the father accessible to him or her. This brings the total engagement and accessible time to about 2.5 hours on a weekday and 6.3 hours on a weekend day. The level and nature of father's involvement vary by children's age and gender. Our results show that fathers in intact families are involved in a wide array of activities other than play and companionship activities.

Although cross-study comparisons are problematic because of the nature of the sample and methods used in collecting data on father involvement, our results show a higher level of fathers' involvement relative to that of mothers' than most previous literature that we can obtain for intact families. Pleck's review of studies conducted in the 1970s and 1980s (1997), based on selective samples, shows a paternal engagement level ranging from $30 \%$ to $45 \%$ and an outlier estimate of $83 \%$ in McBride and Mills (1993) for a small middle-class White sample. Our analyses based on national time-diary data collected in 1997 indicate that the relative time fathers in intact families were directly engaged with children was $67 \%$ that of mothers' on weekdays and $87 \%$ that of mothers' on weekends. Unfortunately, we are unable to be precise about how much of this reported 


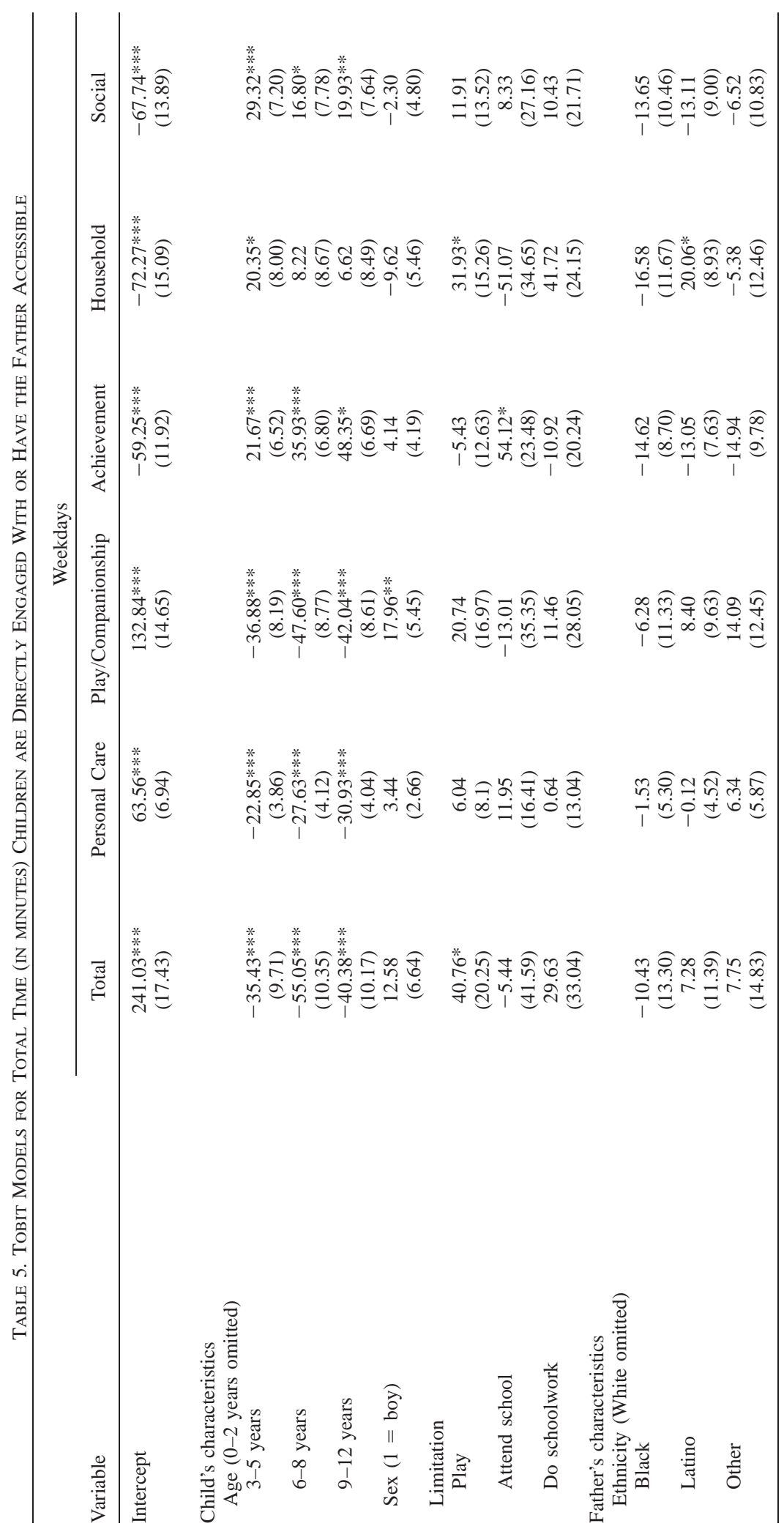




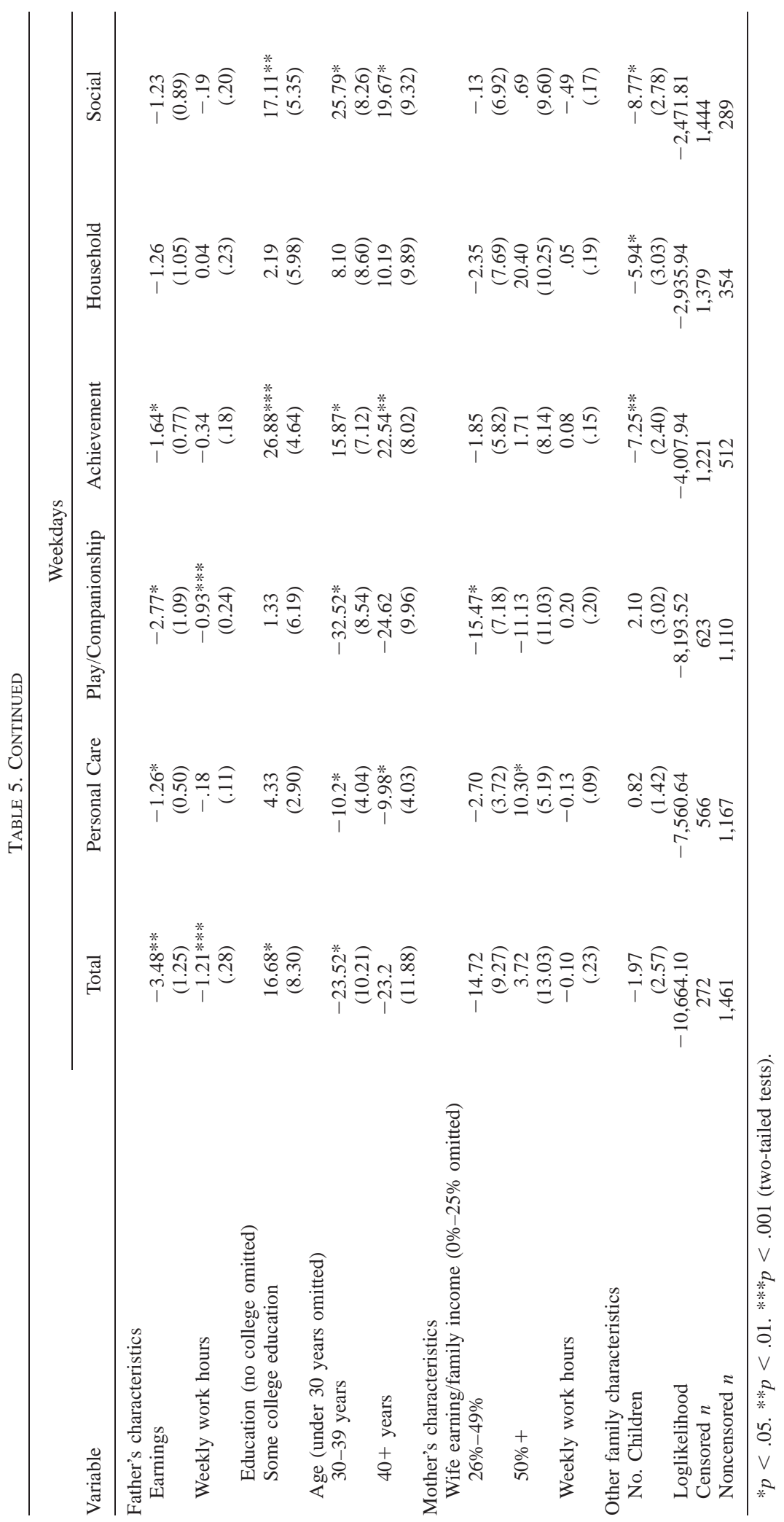




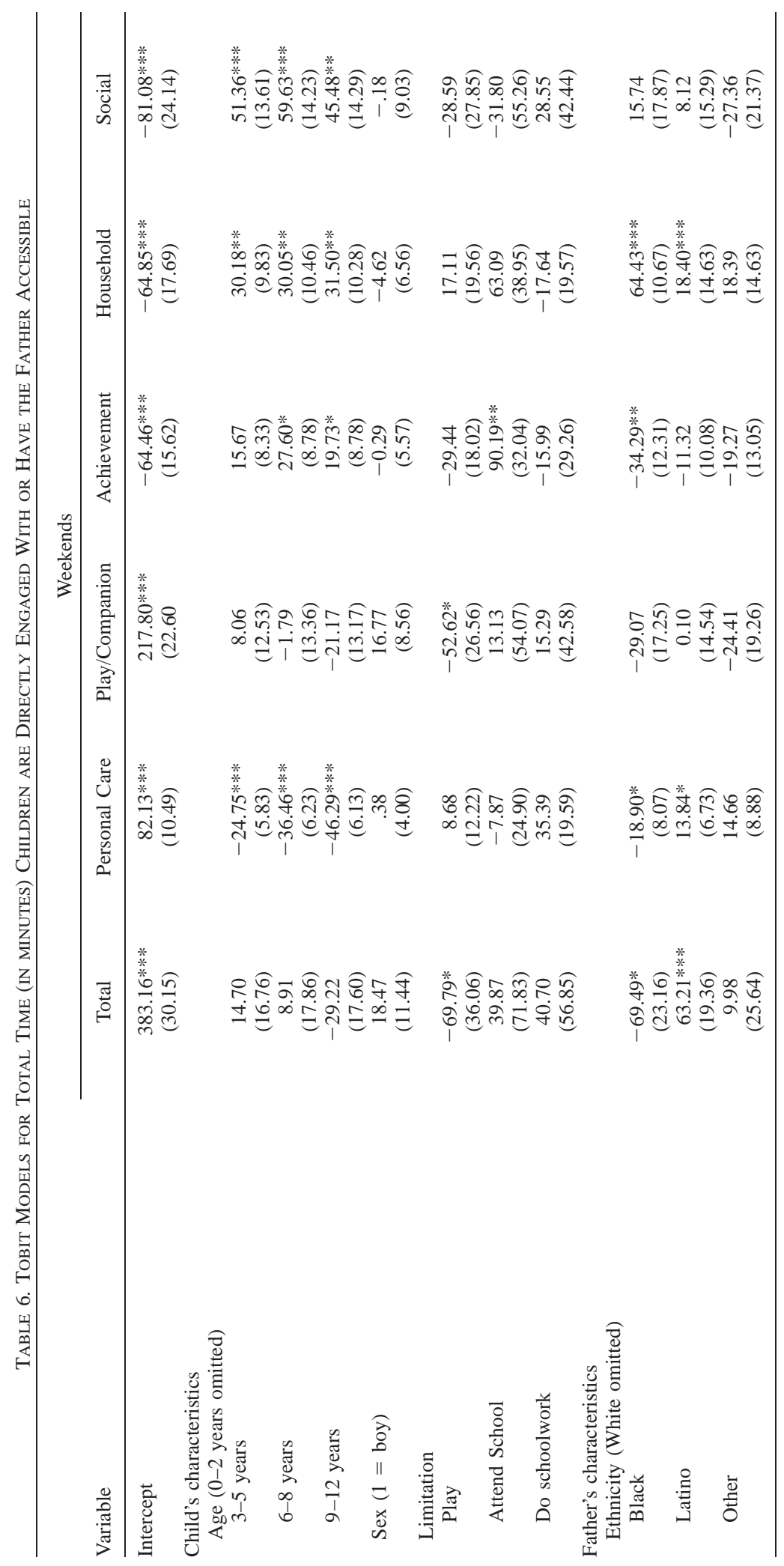




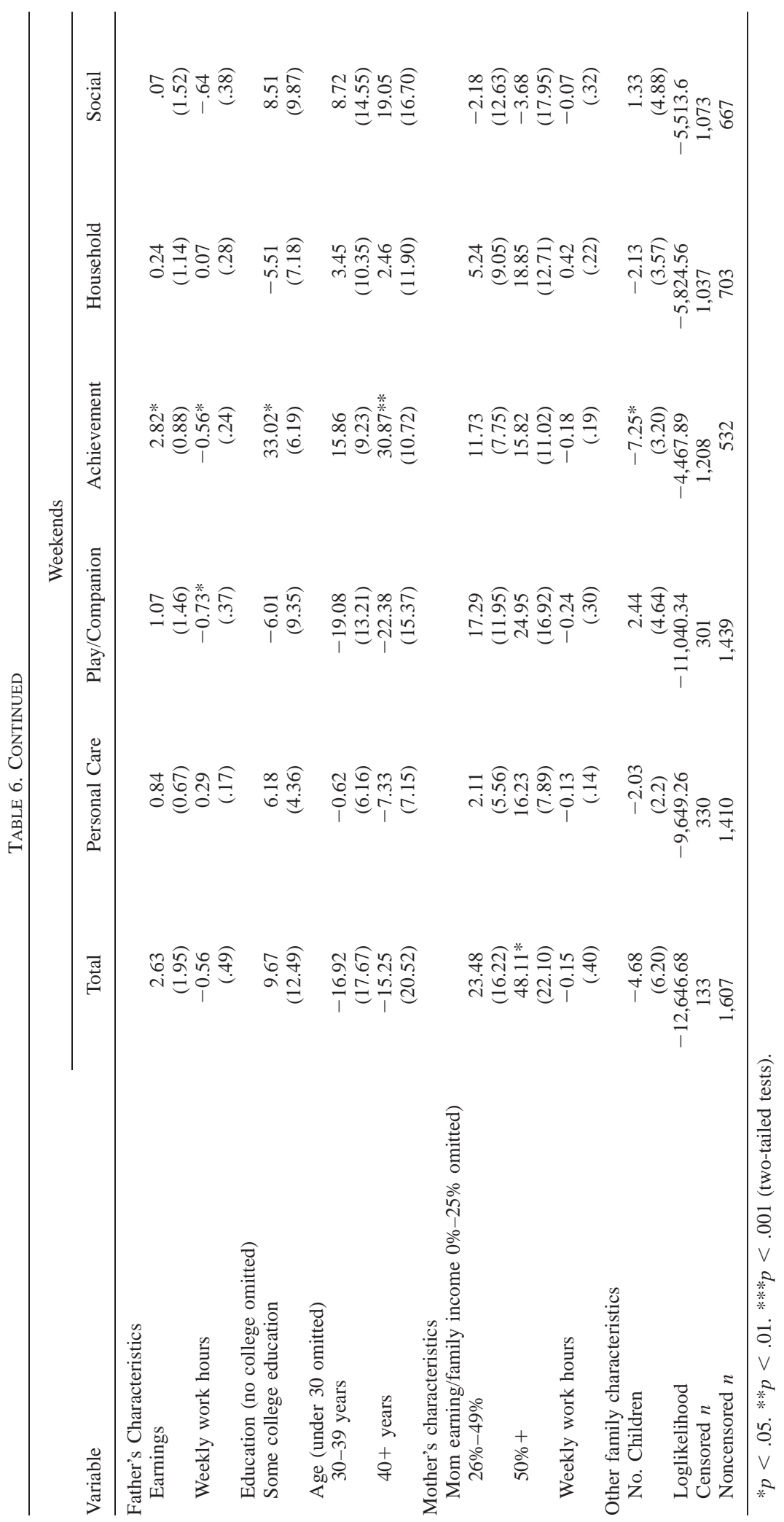


upward trend is due to methodology differences as opposed to a result of change in gender-role ideology and a greater participation of women with children in the labor force in the past few decades. Relative to earlier studies, we place greater confidence in the quality of data used in our analysis both because of the nationally representative sample and the fact that previous methodological evidence using time diaries has yielded more reliable data. It is worthy of note that despite a seemingly overall increase in the relative involvement of fathers, household activities, caring for infants, studying, and reading remain domains in which fathers have a very low relative contribution.

Our multivariate analyses indicate that parents' earnings and labor market behavior influence children's involvement with fathers differently on weekdays and on weekends. On weekdays, fathers' earnings and work hours have a significant negative effect on their involvement with a child, but mothers' work hours or earnings do not. Thus, despite women's increasing role in the labor market, most mothers remain the primary caregivers of young children on weekdays. This finding reminds us of the "time squeeze" phenomenon experienced by working women in the 1980s described in Juster and Stafford (1991).

Although mothers still shoulder the lion's share of the parenting on weekdays, fathers do become more equal partners in caring for children on weekends. The negative effect of fathers' earnings does not carry over to weekends. The work hours of the mothers do not have any effect on fathers' involvement, but when mothers contribute a substantial share of the total family income, fathers become more involved with their children on weekends. These results lend some support to the family economic bargaining models, but the weekend-weekday difference in mothers' income effect also suggests that there are factors other than earnings of parents that determine how involved fathers are with their children. Psychological variables such as gender-role orientation and parenthood ideology are important factors to be examined in future studies. One explanation for the different time allocation patterns during weekends is that parents still view childrearing responsibility as the primary responsibility for mothers and only a secondary role for fathers. Only on weekends, when fathers are not constrained by their market work, do fathers share the childrearing responsibilities in a substantial way. This study, however, cannot directly test this hypothe- sis because of the lack of data in parents' work schedules over the week. The weekday-weekend differential in children's time with fathers also suggests that a simple gender inequality theory is not sufficient to explain the household division of labor in today's American families. Our analyses reveal the inadequacy of most current theories of gender differences in household labor in their failure to distinguish workdays from weekends.

Taken as a whole, our results suggest that a "new father" role envisioned by Goldsheider and Waite (1991) is starting to emerge in intact families on weekends. Whether this more egalitarian division of labor in domestic responsibilities will extend to regular workdays remains to be seen. An important area of study for future research will be to compare paternal involvement in intact families with that in stepparent and single-parent families.

\section{Note}

Funding for this article was provided by Grant ROlHD33474 and Grant RO3HD3886001 from the National Institute of Child and Human Development and the Angus Campbell Fellowship. We acknowledge the research assistance provided by Randy Herbison, YunSan Tsai, and Jonathan Finkelstein and the helpful comments of Pamela Smock, Frank Mott, and Frank Stafford.

\section{REFERENCES}

Acock, A. C., \& Demo, D. H. (1994). Family diversity and well-being. Thousand Oaks, CA: Sage.

Ahmeduzzaman, M., \& Roopnarine, J. L. (1992). Sociodemographic factors, functioning style, social support, and fathers' involvement with preschoolers in African-American families. Journal of Marriage and the Family, 54, 699-707.

Allen, W. R., (1987). Mom's, dad's and boys: Race and sex differences in the socialization of male children. In L. E. Gary (Ed.) Black Men (pp. 99-114). Beverly Hills, CA: Sage.

Almeda, D. M., \& Galambos, N. L. (1991). Examining father involvement and the quality of father-adolescent relations. Journal of Research on Adolescence, $1,155-172$.

Bailey, W. T. (1993). Fathers' knowledge of development and involvement with preschool children. Perceptual and Motor Skills, 77, 1032-1034.

Barnett, R. C., \& Baruch, G. B. (1987). Determinants of father's participation in family work. Journal of Marriage and the Family, 49, 29-40.

Beitel, A. H., \& Parke, R. D. (1998). Paternal Involvement in Infancy; The Role of Maternal and Paternal Attitudes. Journal of Family Psychology, 12,(2), 268-288.

Blair, S. L., Wenk, D., \& Hardesty, C. (1994). Marital quality and paternal involvement: Interconnections of men's spousal and parental roles. Journal of Men's Studies, 2, 221-237. 
Coverman, S. (1985). Explaining husbands' participation in domestic labor, Sociological Quarterly, 26, 81-97.

Farkas, G. (1976). Education, wage rates, and the division of labor between husband and wife, Journal of Marriage and the Family, 38, 473-483.

Furstenberg, F. F., Jr. (1988). Good dads-bad dads: Two faces of fatherhood. In A. J. Cherlin (Ed.), The changing American family and public policy (pp. 193-218). Washington, DC: Urban Institute Press.

Goldscheider F. K., \& Waite, L. J. (1991). New families, no families? Berkeley: University of California Press.

Gottfried, A. E., Bathurst, K., \& Gottfried, A. W. (1994). Role of maternal and dual-earner employment status in children's development. In A. E. Gottfried \& A. W. Gottfried (Eds.), Redefining families: Implications for children's development (pp. 55-97). New York: Plenum Press.

Gustafsson, S. S., \& Stafford, F. P. (1997). Childcare, human capital and economic efficiency. In I. Persson \& C. Jonung (Eds.), Economics of the family and family policies. (pp. 139-158). London and New York: Routledge.

Haas, L. (1998, November). Understanding fathers' participation in childcare: A social constructionist perspective. Paper presented to the National Council on Family Relations, Philadelphia, PA.

Harris, K. M. (1996). Poverty, paternal involvement, and adolescent well-being. Journal of Family Issues, 17(5), 614-640.

Hochschild, A., \& Machung, A. (1989). The second shift: working parents and the revolution at home. New York: Viking.

Hofferth, S. L., Davis-Kean, P., Davis, J., \& Finkelstein, J. (1998). Child development supplement to the Panel Study of Income Dynamics, 1997 [users guide]. Ann Arbor, MI: Institute for Social Research, University of Michigan. Retrieved September 17, 2000 from the World Wide Web:http://www.isr.umich.edu/src/child-development/home.html

Ishii-Kuntz, M. (1994). Paternal involvement and perception toward fathers' roles: A comparison between Japan and the United States. Journal of Family Issues, 15, 3048.

Juster, F. T. (1985). The validity and quality of time use estimates obtained from recall diaries. In T. F. Juster \& F. P. Stafford (Eds.), Time, goods, and well being. Ann Arbor, MI: Institute for Social Research, University of Michigan.

Juster, F. T., \& Stafford, F. P. (1991). The allocation of time: empirical findings, behavioral models, and problems of measurement, Journal of Economic Literature, XXIX, 471-522.

Lamb, M. E., Hwang, P., Broberg, A., Brookstein, F., Hult, G., \& Frodi, M. (1988). The determinations of paternal involvement in a representative sample of primiparouse Swedish families. International Journal of Behavior and Development, 2, 433-449.

Lamb, M. E., Pleck, J. H., Charnov, E. L., \& Levine, J. A. (1985). Paternal behavior in humans. American Zoologist, 25, 883-894.

Lamb, M. E., \& M. B. Stevenson. (1978). Father-infant relationships: Their nature and importance. Youth and Society, 9, 277-297.

Levant, R. F., Slattery, S. C., \& Loiselle, J. E. (1987). Fathers' involvement in housework and childcare with school-aged daughters. Family Relations, 36, 152-157.

Lundberg, S., \& Pollak, R. A. (1997). Bargaining and dis- tribution in marriage. In I. Persson \& C. Jonung (Eds.), Economics of the family and family policies. London: Routledge Press.

Marsiglio, W. (1991). Paternal engagement activities with minor children. Journal of Marriage and the Family, 53, 973-986.

McAdoo, J. L. (1988). The roles of Black fathers in the socialization of Black children. In H. P. McAdoo (Ed.), Black family (pp. 257-269). Newbury Park, CA: Sage.

Manke, B., Seery, B. L., Crouter, A. C., \& McHale, S. M (1994). The three corners of domestic labor: Mothers', fathers', and children's weekday and weekend housework. Journal of Marriage and the Family, 56, 657668

McBride, B. A., \& Mills, G. (1993). A comparison of mother and father involvement with their preschool age children. Early Childhood Research Quarterly, 8, 457477.

Mincer, J., \& Polacheck, S. (1974). Family investments in human capital, earnings of women. Journal of Political Economy 81, 76-108.

Nock, S. L., \& Kingston, P. W. (1988). Time with children: The impact of couples' work-time commitments. Social Forces, 67, 59-85.

Pleck, J. H. (1985). Working wives, working husbands. Beverly Hills, CA: Sage.

Pleck, J. H. (1997). Paternal involvement: Levels, sources, and consequences. In The role of the father in child development. New York: Wiley.

Presser, H. B. (1988). Shift work and child care among young dual-earner American parents. Journal of Marriage and the Family, 50, 133-148.

Radin, N. (1993). Paternal involvement, maternal employment, and adolescents' academic achievement: An 11year follow-up. American Journal of Orthopsychiatry, 63, 306-312.

Robinson, J. P. (1985). The validity and reliability of diaries versus alternative time use measures. In T. F. Juster \& F. P. Stafford (Eds.), Time, goods, and well-being. Ann Arbor, MI: Institute for Social Research, University of Michigan.

Robinson, J. P., \& Godbey, G. (1997). True for life: The surprising ways americans use their time. University Park, PA: Pennsylvania State University Press.

Roopnarine, J. L., \& Ahmeduzzaman, M. (1993). Puerto Rican fathers' involvement with their preschool-age children. Hispanic Journal of Behavioral Science, 15(1), pp. $96-107$

Snarey, J. (1993). How fathers care for the next generation. Cambridge, MA: Harvard University Press.

Stafford, F. P., \& Duncan, G. J. (1985). The use of time and technology by households in the United States. In T. F. Juster \& F. P. Stafford (Eds.), Time, goods, and well-being. Ann Arbor, MI: Institute for Social Research, University of Michigan.

Timmer, S. G., Eccles, J., \& O'Brien, K. (1985). How children use time. In T. F. Juster \& F. P. Stafford (Eds.), Time, goods, and well-being. Ann Arbor, MI: Institute for Social Research, The University of Michigan.

Tinsley, Barbara J., \& Parks, R. D. (1987). Grandparents as interactive and social support agents for families with young infants. International Journal of Aging and $\mathrm{Hu}$ man Development, 25(4), 259-77

Yeung, W. J., Duncan, G. J., \& Hill, M. S. (1999). Putting fathers back in the picture. Journal of Marriage and the Family, 49(2),97-114. 